\title{
18. An economic analysis of the sudden influx of Korean female golfers into the LPGA \author{
and Younghan Lee*
} \\ Young Hoon Lee, Ilhyeok Park, Joon-Ho Kang
}

\subsection{INTRODUCTION}

The US Ladies Professional Golf Association (LPGA) tour was founded in 1950 and has since developed into one of the most popular golf events in the world. Its annual purse is the largest among women's golf tours. Historically, most LPGA members have been American and, until 1980, 90 percent of total tournaments were won by American golfers. Since then, the LPGA Tour has been experiencing rapid globalization, especially in the 2000s. Female golfers from various countries have earned LPGA Tour cards and non-US golfers have now won more tournaments than US golfers.

At first, the number of foreign golfers increased slowly, with most of them coming from Europe and Australia. In contrast, in the last decade, Asian women have flooded into the LPGA Tour. As a result, in 2010, approximately half of the top-10 golfers in most tournaments were Asian, and most of these were Korean.

The influx of Korean golfers may signal a significant shift in the revenue structure of the LPGA, which is a critical concern for the LPGA's business model. In particular, the success of Korean women in the LPGA has increased the proportion of its revenues that come from Korea. Since Se Ri Pak won her first championship at the McDonald's LPGA Championship in 1998, every LPGA tournament has been televised live in Korea. The value of Korean broadcasting rights has increased accordingly. In 1994, Korean LPGA broadcasting rights were valued at only $\$ 60,000$, but they rose to $\$ 2.25$ million in 2009 and to more than $\$ 4.0$ million in 2010 (Yonhap News, 2009).

Korean companies began to sponsor LPGA events in 1995 (for example, Samsung World Championship), and they have since sponsored two or three events every year. Should this trend continue, it may cause the LPGA to lose a significant portion of its US-derived revenue. As the number of 
tournaments won by US golfers falls, the number of LPGA fans in the US might fall as well. Among the 25 tournaments comprising the 2011 LPGA Tour, only 13 are held in the US. This reflects a large decrease from the 2008 tour, which consisted of 34 tournaments, almost all of which were held in the US. The recession is a clear cause of this change (though the number of the PGA tournaments has remained constant throughout the Great Recession), but the influx of Korean golfers into the LPGA is at least a partial cause. Therefore, the overall effect of the influx of Korean golfers on the LPGA revenue may prove, in the aggregate, to be negative.

One rationale for the revenue decline in the United States is consumer discrimination. Studies of several sports have found evidence of fan discrimination based on nationality or race (for example, Medoff, 1986; Nardelli and Simon, 1990; Hamilton, 1997). Forley and Smith (2007) show that Major League Baseball fans engage in consumer discrimination. In particular, fans of the Boston Red Sox attend fewer baseball games when Hispanic players are added to the roster. Kanazawa and Funk (2001) analyze Nielsen ratings for National Basketball Association games and find strong evidence that greater participation by white players causes viewership to increase and that the marginal revenue product of white players exceeds that of comparable black players. If golf fans in the US also discriminate on the basis of race or nationality, demand for the LPGA Tour must also decrease, ceteris paribus. (See Greenhaus et al., 1990, and Arrow, 1998, for a discussion of discrimination in a broader context.)

The principal objective of this chapter is to analyze the possible causes of the influx of Korean women golfers into the LPGA. We also address two related questions. The first question is why the influx of Korean golfers is so much larger in the LPGA than in the men's Professional Golf Association (PGA). The second question is why Japanese women have not also entered the LPGA in large numbers. The Japanese Ladies' Professional Golf Association (JLPGA) tour has grown into the secondrichest women's professional tour. This indicates that many Japanese women have world-class skills, but - for some reason - they have largely stayed in Japan. We assess the incentives of Korean and Japanese golfers to switch labor markets from their homeland's golf tours to the LPGA Tour. Many have argued that the influx can be explained by the success of Se Ri Pak, which encouraged young Korean golfers to follow in her footsteps. Jiyai Shin, another star Korean golfer, stated in an interview:

I saw Se Ri Pak winning the 1998 (US open) event. It was amazing for me, because before Se Ri Pak's wonderful performance, I never knew that the sport of golf even existed. I watched it on TV and thought that golf seems to be a very 
interesting game. Since the Se Ri Pak syndrome, my friends, Inbee Park and many others pursued a career in golf. Actually, Se Ri Pak is our idol. (USGA, US Women's Open Website, 2009)

Taking Jiyai Shin's statement into consideration, we briefly discuss the effect of Se Ri Pak's success on the influx of Korean women in LPGA.

A seminal paper by Roy (1951) discussed occupational choice with heterogeneous skills. In his discussion regarding self-selection between fishing and hunting, Roy demonstrated that workers self-select the sector that provides them with the highest expected earnings. Borjas $(1987,1994)$ used Roy's framework to lay out a simple two-sector model of immigration. We use the Borjas model to explain the switch from the Korean Ladies' Professional Golf Association (KLPGA) to the LPGA. According to the decision rule in Borjas (1987), the difference in the average earnings in the two countries is not the only factor that potential migrants consider. The earning distributions are also critical. For example, a top golfer in the KLPGA would be reluctant to move into the LPGA even though the average earnings in the LPGA are greater than in the KLPGA if the variance of earnings in the LPGA is very small or the correlation of random factors between two tours is negative. We assess the labor market switch by comparing all the relevant determinants of migration from the KLPGA to the LPGA.

Section 18.2 provides a historical overview of Korean women players' performance in the LPGA. Section 18.3 discusses possible causes of their move to the LPGA and explains why similar moves did not occur in Japan. We also review the immigration decision model of Borjas (1987) and apply it to LPGA and KLPGA data, most of which are obtained from the official websites of US LPGA and KLPGA. In Section 18.4, we assess the competition levels for both genders' golf tours in Korea and the US and the implications for migration patterns. We then evaluate the unique skills of Korean golfers who migrate. Section 18.5 concludes. We predict that the influx of Korean golfers will ultimately decline and that some Korean golfers will return to the KLPGA or move to the Japanese tour.

\subsection{HISTORICAL OVERVIEW OF KOREAN WOMEN GOLFERS IN THE LPGA}

The LPGA Tour is one of the most popular golf events in the world, attracting the world's best female golfers. They are drawn by the tour's long history, the prestige of the association, and the large purses. The first foreigner to win an LPGA title was Fay Crocker from Uruguay, in the 


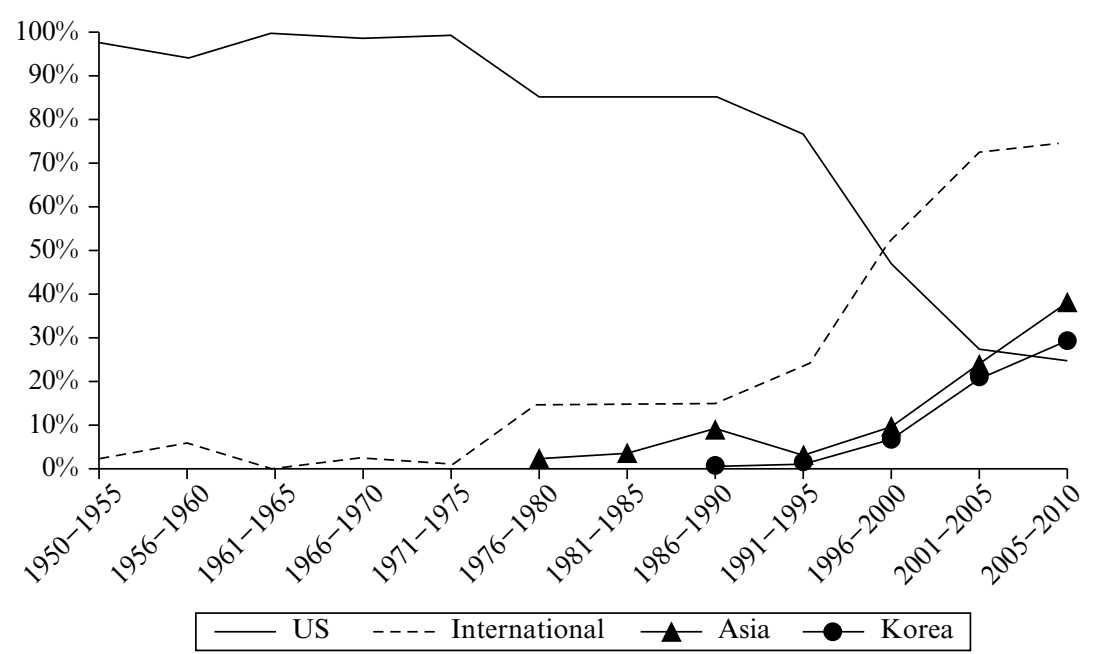

Source: Created by the authors based on the data from the official US LPGA website.

Figure 18.1 LPGA titles earned by US, international, Asian, and Korean golfers

1955 Serbin Open. A Japanese golfer, Hisako Higuchi became the first Asian golfer to ever win an LPGA tournament when she won the 1976 Colgate European Open. Since then, Asian players have won 143 titles (7.7 percent), with most of those wins occurring within the past decade. China, Japan, South Korea, the Philippines, Taiwan, and Thailand have all produced female golfers who have won at least one LPGA title, but most wins have been secured by Korean women. Koreans won a total of 93 titles, corresponding to 5 percent of all tournaments and to 65 percent of all Asian wins between 1950 and 2010.

Figure 18.1 shows the recent change in the number of titles won by players of different nationalities. It presents the percentage of titles won by US, international (non-US), Asian, and Korean players in five-year blocks. Until 1995, there were no significant changes, except that nonAsian international golfers (which, in this case, means European and Australian golfers) won about 10 percent of tournaments in the 1976-90 period. In 1996, the percentage of titles won by international (non-US) players started to increase rapidly. Between 2005 and 2010, more Asian players than US players won LPGA titles. Since 1998, the year in which Se Ri Pak won her first LPGA title, most of the titles won by Asians have gone to Koreans (80.4 percent of Asian wins).

Because a high percentage of titles can be won by a few superstars, we 
Handbook on the economics of women in sports

Table 18.1 Percentage of top 10 LPGA finishes by nationality

\begin{tabular}{lcllrrc}
\hline Year & $\begin{array}{c}\text { No. of } \\
\text { tournaments }\end{array}$ & US & Korea & Sweden & Australia & Others \\
\hline 2001 & 34 & $54.5(218 / 58)$ & $8.8(35 / 7)$ & $11.0(44 / 7)$ & $6.0(24 / 6)$ & $19.8(79 / 25)$ \\
2002 & 31 & $44.7(156 / 52)$ & $15.5(54 / 8)$ & $12.0(42 / 9)$ & $8.3(29 / 8)$ & $19.5(68 / 21)$ \\
2003 & 31 & $40.4(137 / 49)$ & $24.2(82 / 14)$ & $7.4(25 / 9)$ & $8.8(30 / 9)$ & $19.2(65 / 18)$ \\
2004 & 32 & $36.9(130 / 48)$ & $23.9(84 / 14)$ & $8.8(31 / 6)$ & $5.6(20 / 5)$ & $24.7(87 / 10)$ \\
2005 & 30 & $37.2(132 / 33)$ & $25.6(91 / 16)$ & $12.1(43 / 8)$ & $5.4(19 / 7)$ & $19.7(70 / 20)$ \\
2006 & 33 & $39.0(143 / 35)$ & $28.3(104 / 23)$ & $9.3(34 / 8)$ & $5.4(20 / 5)$ & $18.0(66 / 21)$ \\
2007 & 31 & $36.7(119 / 27)$ & $25.0(81 / 22)$ & $10.8(35 / 7)$ & $6.5(21 / 6)$ & $21.0(68 / 17)$ \\
2008 & 34 & $33.7(123 / 35)$ & $29.9(109 / 23)$ & $9.6(35 / 9)$ & $5.8(21 / 6)$ & $21.1(77 / 17)$ \\
2009 & 28 & $29.0(86 / 25)$ & $31.6(94 / 27)$ & $9.8(29 / 7)$ & $4.4(13 / 3)$ & $25.3(75 / 16)$ \\
2010 & 24 & $26.6(71 / 21)$ & $39.7(106 / 19)$ & $3.7(10 / 4)$ & $4.9(13 / 4)$ & $25.1(67 / 19)$ \\
\hline
\end{tabular}

Note: Numbers include only official tournaments and exclude match play games. The total numbers of top 10 exceed the 'number of tournament $\times 10$ ' because many players were tied for 10th place. The numbers in columns 3-7 are the number of top 10 finishes by a given country divided by the total number of top 10 finishes. For example 218/400 $=0.545$.

The numbers in parentheses are (number of top 10/number of players).

report the percentages of top 10 finishes in Table 18.1 to illustrate the recent success of Korean players more completely. The percentage of top 10 finishes (incidence count, not head count) by Koreans has increased steadily over the past decade. In the 2001 Tour, 54.5 percent of all top 10 scores were by US golfers; Korean women golfers accounted for only 8.8 percent. On the 2010 tour, the percentage of Korean golfers in the top 10 rose to 39.7 percent, whereas US golfers secured only 26.6 percent of the top 10 finishes. During these 10 seasons, the percentages of the Korean and US golfers increased by 450 percent and decreased by 50 percent, respectively.

Table 18.2 shows the top 10 money winners in selected years. In 2001, Annika Sorenstam was the top prize winner, earning \$2.1 million. The US and Korea put three and two golfers, respectively, in the top 10 in that year. In 2010, there were two Americans (Cristie Kerr and Michelle Wie) and four Koreans in the top 10 money winners. Moreover, many Korean women are succeeding on the LPGA Tour, while most other countries have only one or two standout players, such as Annika Sorenstam of Sweden, Karrie Webb of Australia, and Lorena Ochoa of Mexico. The US and Korea are the only two countries with more than 20 players in the list of top 10 finishers; no other country has had more than 10 players on the list (see the numbers after the slash in the brackets of Table 18.1).

The influx of Korean players is also evident in Figure 18.2, which shows the total number of qualified Korean players in the LPGA. The 


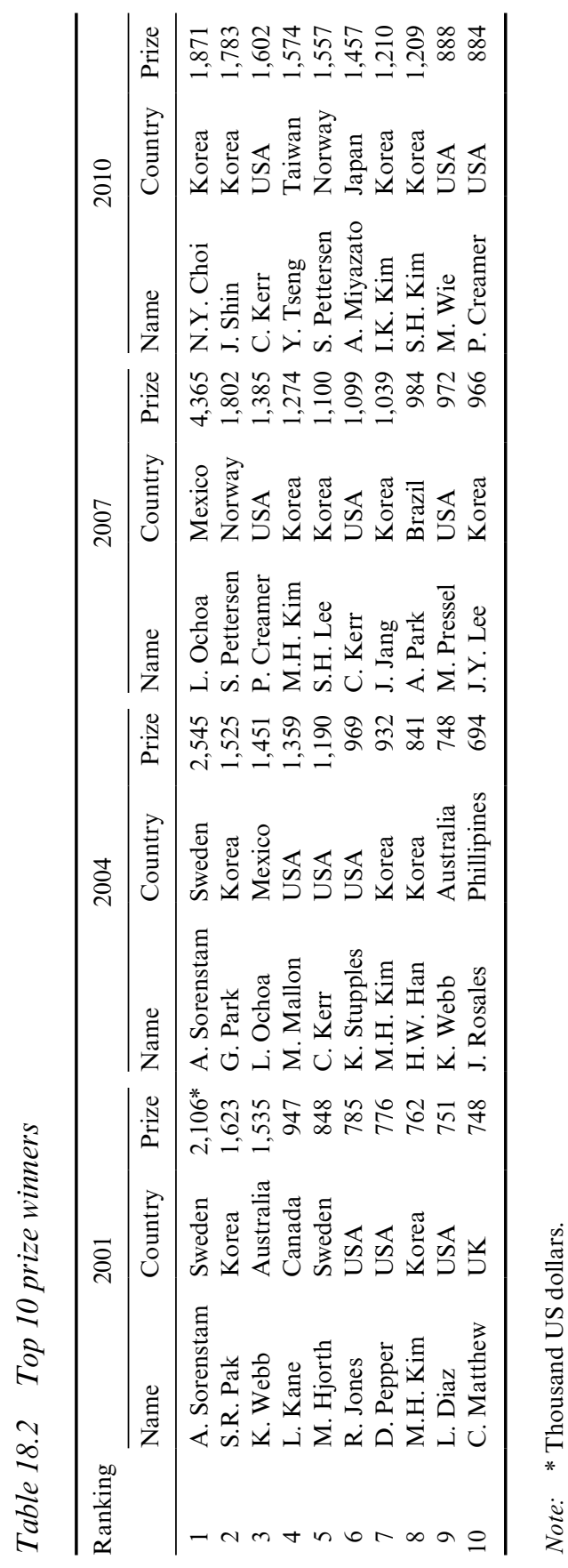




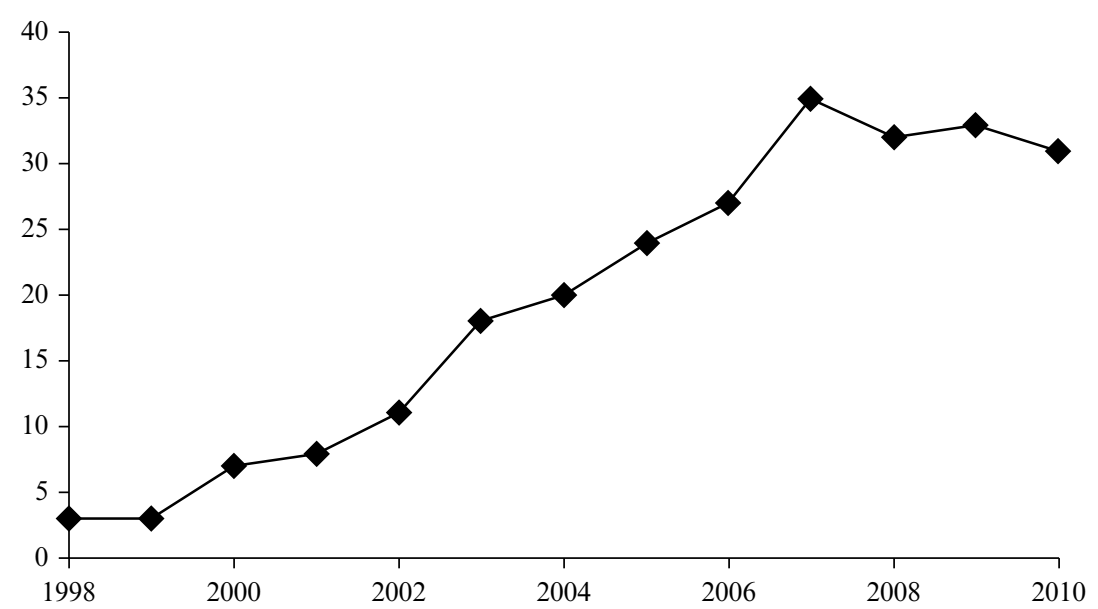

Source: Created by the authors based on the data from the official US LPGA website.

Figure 18.2 Number of Korean players in LPGA Tour by year

total number increased steadily from 1998 to 2007, when it reached the maximum of 35 players. The data confirm the flood of Korean golfers into the LPGA.

\subsection{POSSIBLE CAUSES OF THE INFLUX}

In order to uncover the possible causes of the influx of Korean women into the LPGA, we discuss the maturity of the KLPGA, compare prize money and competition level in the LPGA and KLPGA, and contrast the KLPGA with the JLPGA. We analyze the above factors in the framework of the Borjas self-selection model of immigration. Therefore, we first present the Borjas model and then apply it to the issues we examine.

\subsubsection{The Immigration Decision Model}

Borjas (1987) lays out a simple, two-sector Roy model to analyze immigration. He shows that immigrants differ systematically from the overall populations of both their native and new countries. In particular, people whose earnings are either artificially suppressed in their home country or whose skills are particularly well-suited to their destination country are more likely to immigrate. We apply this model to the golfers' decision 
to switch from the KLPGA to the LPGA. The earnings in KLPGA and LPGA are:

$$
\begin{gathered}
w_{K}=\mu_{K}+\varepsilon_{K}, \\
w_{U S}=\mu_{U S}+\varepsilon_{U S},
\end{gathered}
$$

where $\mu_{K}$ is the average earnings for all Korean women in KLPGA and $\mu_{U S}$ is what their average earnings would be if they all moved to the LPGA. The random 'error' terms refer to individual-specific abilities in the KLPGA and LPGA. They are distributed $\varepsilon_{k} \sim N\left(0, \sigma_{k}\right)$ and $\varepsilon_{u s} \sim N\left(0, \sigma_{u s}\right)$ and have the correlation coefficient $\rho$. Korean women who are active in the KLPGA migrate to the LPGA when the net impact on pay, given by the index function $I$, is positive:

$$
I=\left(\mu_{U S}-\mu_{K}-\pi\right)+\left(\varepsilon_{U S}-\varepsilon_{K}\right),
$$

where $\pi$ is a time-invariant measure of the cost of moving to LPGA. Therefore, the probability that a golfer moves from the KLPGA to the LPGA is given by:

$$
P=\operatorname{Pr}[I>0]=1-\Phi(z),
$$

where $z=-\left(\mu_{U S}-\mu_{K}-\pi\right) / \sigma_{v}, v=\varepsilon_{U S}-\varepsilon_{K}$, and $\Phi$ is the standard normal distribution function. Equation (18.4) implies that the migration decision depends on both the average earnings gap $\left(\mu_{U S}-\mu_{K}-\pi\right)$ and the earnings distributions of the two Tours. Specifically, migrants are likely to fall in the upper tail of the distribution $\Phi(z)$. Migrants are therefore more likely to succeed in the LPGA than the average Korean member of the KLPGA. This self-selection means that the conditional expected earnings of migrants is greater than $w_{k}$. Equation (18.5) gives the counterfactual expectation of what Korean golfers would earn had they not moved to the LPGA, while equation (18.6) shows the expected earnings of Korean golfers in the LPGA:

$$
\begin{gathered}
E\left[w_{K} \mid I>0\right]=\mu_{K}+\frac{\sigma_{K} \sigma_{U S}}{\sigma_{v}}\left(\rho-\frac{\sigma_{K}}{\sigma_{U S}}\right) \lambda, \\
E\left[w_{U S} \mid I>0\right]=\mu_{U S}+\frac{\sigma_{K} \sigma_{U S}}{\sigma_{v}}\left(\frac{\sigma_{U S}}{\sigma_{K}}-\rho\right) \lambda,
\end{gathered}
$$


where $\lambda=\phi(z) /[1-\Phi(z)]$, and $\phi$ is the probability density function of the standard normal distribution.

The second terms in equations (18.5) and (18.6) reflect self-selection, which depends upon the variances and correlation coefficient in the earning distributions of KLPGA and LPGA as well as the net average difference in earnings. The expected increase in earnings by Korean golfers who move to the LPGA is particularly large if any of three conditions holds. First, the expected gain in earnings grows as the average earnings gap, $w_{U S}-w_{K}$, grows. That is, a Korean migrant will earn more if she moved. Second, she expects to gain more as the earning variance in LPGA $\left(\sigma_{U S}^{2}\right)$ grows. This occurs because, due to self-selection, a woman who migrates expects to be in the upper end of the distribution of the LPGA. The greater the variance of earnings in the LPGA, the greater her gain will be. Finally, a migrant expects to gain more as the earning variance in KLPGA $\left(\sigma_{K}^{2}\right)$ shrinks. This condition is the flipside of the previous condition. As the distribution of earnings in Korea condenses, the winnings of those who are in the upper tail fall, reducing the benefits of staying in Korea.

We analyze the distributions of prize earnings in the KLPGA and LPGA by using data from the 2000s. Unlike averages and variances of earnings in KLPGA and LPGA, the correlation coefficient of $\varepsilon_{K}$ and $\varepsilon_{U S}$ is not observed. The correlation is a critical factor in the migration decision since it determines where a golfer who is currently in the KLPGA would be located in the earning distribution in the LPGA. For example, a golfer in the top 5 percent of the KLPGA prize money may be reluctant to move to the LPGA without knowing $\rho$ even if the average and variance of earnings in the LPGA are greater than those in KLPGA because she fears that even top Korean golfers will not do well in the LPGA. Therefore, we need to address Korean golfers' expectations of $\rho$.

\subsubsection{The Growing Maturity of the KLPGA}

As can be noted from Jiyai Shin's remarks, Se Ri Pak was a catalyst for the influx of Korean women into the LPGA. However, such motivation itself could not have produced so many competitive golfers unless the KLPGA was already mature - that is, unless its members were sufficiently skilled. Therefore, a necessary condition for the influx is that the KLPGA Tour produces golfers who can compete in the LPGA.

When the KLPGA was founded in 1978 with only eight professional golfers, it staged very few events. Table 18.3 shows the number of members and tournaments in the KLPGA by five-year intervals. By 1995, only 119 members had passed the qualifying test. However, beginning in the mid- 
Table 18.3 Number of KLPGA members and KLPGA tournaments

\begin{tabular}{lccc}
\hline Year & New members & $\begin{array}{c}\text { Cumulative no. of } \\
\text { members }\end{array}$ & $\begin{array}{c}\text { Annual no. of } \\
\text { tournaments }\end{array}$ \\
\hline $1978-1985$ & 29 & 29 & 5.0 \\
$1986-1990$ & 29 & 58 & 8.6 \\
$1991-1995$ & 61 & 119 & 9.0 \\
$1996-2000$ & 114 & 233 & 12.2 \\
$2001-2005$ & 223 & 456 & 14.2 \\
$2006-2010$ & 329 & 785 & 21.6 \\
\hline
\end{tabular}

1990s, this number increased greatly. Some 114 new members joined the KLPGA in 1996-2000, 223 joined in 2001-05, and 329 joined in 2005-10. The 237 percent increase in membership over the past decade means that the golfers who entered the KLPGA during this millennium represent 75 percent of its total membership. The number of tournaments was only in the one-digit range until the early 1990s, but the average number grew to 12.2 in the late 1990 s and 14.2 in the early 2000 s. While the KLPGA Tour had less than half the number of events of the LPGA Tour during this period, most Korean golfers who are now in the LPGA played in the KLPGA Tour.

Figure 18.3 compares the number of tournaments in the four major women's golf Tours. The LPGA and JLPGA hold the most tournaments. The number of tournaments of the KLPGA is approximately half that of the LPGA, but it is comparable to that in the Ladies European Tour (LET). The fact that the Rolex world rankings of women golfers include performance in the KLPGA also supports the argument that the KLPGA is sufficiently mature to produce competitive golfers. The Rolex rankings began in 2006 and include the US LPGA, JLPGA, KLPGA, LET, and Australian LPG Tours in its calculations. Therefore, despite its short history, the KLPGA Tour provides a sufficiently competitive environment for participating golfers to develop their skills and to acquire experience. The existence of the second division of the KLPGA Tour demonstrates its depth and shows that Korean teenagers now have an opportunity to grow as golfers.

\subsubsection{Prize Money, Sponsorship, and the JLPGA}

Se Ri Pak's success in the LPGA made teenage Korean golfers aware of their potential as professional golfers in the LPGA and the lucrative rewards available in the LPGA. That is, Pak's performance helped Korean 


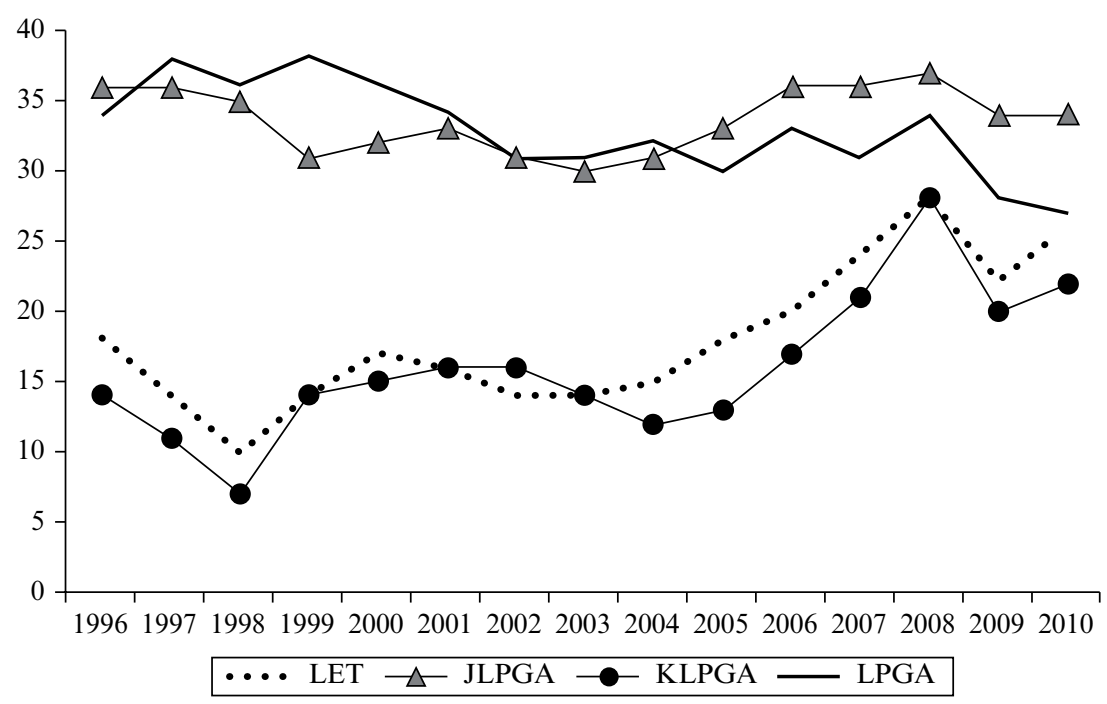

Figure 18.3 Number of tournaments in four different golf Tours

golfers form a large, positive expectation of $\rho$ (the correlation coefficient of $\varepsilon_{K}$ and $\left.\varepsilon_{U S}\right)$. Figure 18.4 compares the annual prize money of the four major women's golf Tours: the LPGA, JLPGA, KLPGA and Ladies' European Tour (LET). The four tours offer widely varying prize money. The LPGA has the largest purse, and the KLPGA has the smallest. In particular, the LPGA's total purse ( $\$ 45.1$ million) was approximately 10 times that of the KLPGA's ( $\$ 4.4$ million) in the 2005 season. Table 18.4 shows that mean prize money of the LPGA was more than 10 times larger than that of the KLPGA in 2004. The difference in expected earnings is even larger in the top 5 and 10 percent of players (Table 18.5). The top 5 and 10 percent of LPGA players earned 11.43 and 11.41 times more than analogous KPLGA players did in 2001. Table 18.4 also shows that, since 2007, the earnings on the two Tours have begun to converge. However, the mean earnings on the LPGA Tour remain almost four times those on the KLPGA Tour. Table 18.5 shows that a similar pattern holds for the expected earnings of the most successful golfers on the Tours.

For simplicity, we assume that $\rho=1$ and the immigration cost is $\$ 100,000$, and we consider the immigration decision in 2010. Setting $\rho=1$ implies that a golfer who is in the 95th percentile in the prize money list of the KLPGA would also be in the 95th percentile of the LPGA. Using data for the top 5 percent (Table 18.5) of players in prize money from the LPGA and the KLPGA, we calculate the index value (equation (18.3)) 


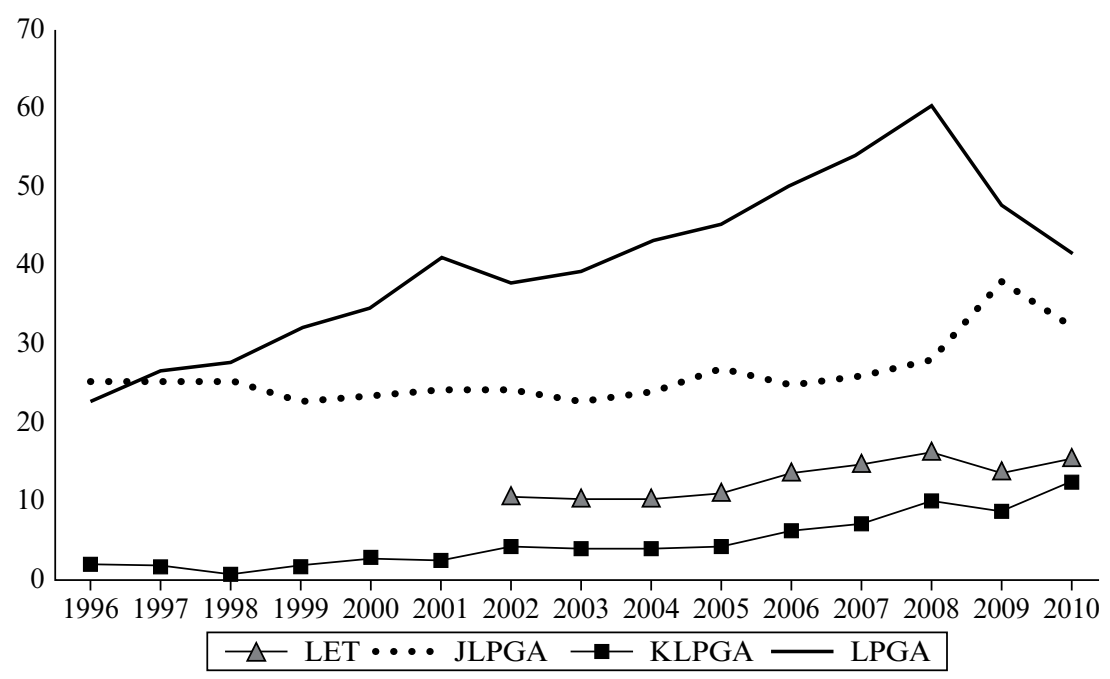

Figure 18.4 Total purse (million US\$) of LPGA, KLPGA, JLPGA and LET

for a golfer on the 95th percentile. The expected net gain for the average golfer is $\left(\mu_{U S}-\mu_{K}-\pi\right)=(230,118-74,591-100,000)=54,474$, and we approximate the difference in error terms given by the difference in average earnings of players in the 95 th percentile, $\left(\varepsilon_{U S}-\varepsilon_{K}\right)=(1,532,837$ $-387,963)=993,081$. This results in the index value $I=1,047,555$.

The variation in prize money in each Tour is another factor in the migration decision. The variation in the LPGA, as represented by the coefficient of variation (CV), was larger than that in the KLPGA until 2006 (see Table 18.4). For example, the CV of the LPGA in 2003 was about 50 percent larger than that of the KLPGA. This means that the LPGA prize money distribution had larger tails at both ends than KLPGA prize money distribution in the early 2000s. As in Borjas (1987, 1994), higher expected earnings and greater variation of expected earnings in the LPGA Tour motivated Korean women to migrate. From the professional golfer's perspective, the LPGA is a more lucrative labor market than the KLPGA. If the competition levels are more or less equal then $\rho$ is positive and close to one. Unlike the expected values, the coefficients of variation have neither converged nor diverged over time. The difference between LPGA and KLPGA started to diminish since around 2007 in terms of both mean prize money and within-Tour variation.

Based on the information in Table 18.4, we calculate the ratio of the variances and the conditional expected earnings (18.5) and (18.6) for a 
Table 18.4 Mean, standard deviation and coefficient of variation of prize money by year

\begin{tabular}{|c|c|c|c|c|c|c|c|c|c|}
\hline \multirow[t]{2}{*}{ Year } & \multicolumn{4}{|c|}{ LPGA } & \multicolumn{4}{|c|}{ KLPGA } & \multirow{2}{*}{$\begin{array}{c}\text { LPGA- } \\
\text { KLPGA } \\
\text { ratio } \\
\text { (means) }\end{array}$} \\
\hline & $\mathrm{N}^{*}$ & Mean** & SD & $\mathrm{CV}^{*}$ & $\mathrm{~N}$ & Mean & SD & $\mathrm{CV}$ & \\
\hline 001 & 203 & $\$ 171,805$ & 278,507 & 1.62 & 102 & $\$ 17,331$ & 22,723 & 1.31 & 9.91 \\
\hline 2002 & 200 & $\$ 170,316$ & 307,171 & 1.80 & 95 & $\$ 19,590$ & 25,937 & 1.32 & 8.69 \\
\hline 2003 & 258 & $\$ 142,212$ & 267,844 & 1.88 & 103 & $\$ 17,207$ & 21,733 & 1.26 & 8.26 \\
\hline 2004 & 193 & $\$ 200,561$ & 315,724 & 1.57 & 103 & $\$ 19,871$ & 24,113 & 1.21 & 10.09 \\
\hline 2005 & 192 & $\$ 204,245$ & 324,254 & 1.59 & 97 & $\$ 26,950$ & 34,644 & 1.28 & 7.58 \\
\hline 2006 & 197 & $\$ 226,344$ & 385,389 & 1.70 & 107 & $\$ 39,365$ & 56,346 & 1.43 & 5.75 \\
\hline 2007 & 190 & $\$ 237,598$ & 430,671 & 1.81 & 116 & $\$ 46,972$ & 87,750 & 1.87 & 5.06 \\
\hline 2008 & 188 & $\$ 282,694$ & 404,520 & 1.43 & 120 & $\$ 58,994$ & 98,028 & 1.66 & 4.79 \\
\hline 2009 & 161 & $\$ 267,665$ & 367,106 & 1.37 & 104 & $\$ 46,524$ & 74,839 & 1.61 & 5.75 \\
\hline 2010 & 161 & $\$ 230,118$ & 363,928 & 1.58 & 105 & $\$ 74,591$ & 91,973 & 1.23 & 3.09 \\
\hline
\end{tabular}

Notes:

* Number of players included in the calculation. Only LPGA members who earn more than $\$ 0$ are included.

** $\quad(N \times$ Mean $)$ is less than actual total purse of each year because only the registered LPGA members are included in the calculation. Part of prize money was earned by non-LPGA members in the tournaments that were co-hosted by LPGA and other countries' association. For example, the 2005 CJ Nine Bridge Classic was held in Korea, and co-hosted by LPGA and KLPGA. Many non-LPGA members won prize money in the tournament.

*** Coefficient of variation (standard deviation/mean).

Table 18.5 Mean of top 5 percent and 10 percent of prize money by year

\begin{tabular}{|c|c|c|c|c|c|c|}
\hline \multirow[t]{2}{*}{ Year } & \multicolumn{3}{|c|}{ Mean of top $5 \%$} & \multicolumn{3}{|c|}{ Mean of top $10 \%$} \\
\hline & LPGA & KLPGA & $\begin{array}{c}\text { LPGA- } \\
\text { KLPGA } \\
\text { ratio }\end{array}$ & LPGA & KLPGA & $\begin{array}{c}\text { LPGA- } \\
\text { KLPGA } \\
\text { ratio }\end{array}$ \\
\hline 2001 & $\$ 1,088,326$ & $\$ 95,245$ & 11.43 & $\$ 839,113$ & $\$ 73,550$ & 11.41 \\
\hline 2002 & $\$ 1,179,358$ & $\$ 111,447$ & 10.58 & $\$ 873,313$ & $\$ 81,433$ & 10.72 \\
\hline 2003 & $\$ 1,066,603$ & $\$ 94,519$ & 11.28 & $\$ 809,453$ & $\$ 72,932$ & 11.10 \\
\hline 2004 & $\$ 1,225,271$ & $\$ 95,547$ & 12.82 & $\$ 926,140$ & $\$ 78,607$ & 11.78 \\
\hline 2005 & $\$ 1,217,071$ & $\$ 141,654$ & 8.59 & $\$ 950,871$ & $\$ 110,039$ & 8.64 \\
\hline 2006 & $\$ 1,595,277$ & $\$ 244,172$ & 6.53 & $\$ 1,180,702$ & $\$ 182,173$ & 6.48 \\
\hline 2007 & $\$ 1,498,639$ & $\$ 338,434$ & 4.43 & $\$ 1,159,133$ & $\$ 228,064$ & 5.08 \\
\hline 2008 & $\$ 1,571,646$ & $\$ 410,121$ & 3.83 & $\$ 1,276,148$ & $\$ 293,717$ & 4.34 \\
\hline 2009 & $\$ 1,447,068$ & $\$ 308,195$ & 4.70 & $\$ 1,209,648$ & $\$ 214,529$ & 5.64 \\
\hline 2010 & $\$ 1,532,837$ & $\$ 387,963$ & 3.95 & $\$ 1,156,656$ & $\$ 306,597$ & 3.77 \\
\hline
\end{tabular}


Table 18.6 Conditional mean earnings in KLPGA and LPGA for golfers moving in $L P G A$

\begin{tabular}{lcccc}
\hline Year & $E\left(w_{U S} / I>0\right)$ & $E\left(w_{K} / I>0\right)$ & $k=\sigma_{U S} / \sigma_{K}$ & $1 / k=\sigma_{K} / \sigma_{U S}$ \\
\hline 2001 & 375.183 & 37.065 & 11.472 & 0.087 \\
2002 & 406.660 & 42.887 & 11.226 & 0.089 \\
2003 & 347.745 & 33.163 & 12.981 & 0.077 \\
2004 & 400.968 & 37.080 & 12.670 & 0.079 \\
2005 & 398.185 & 50.170 & 9.005 & 0.111 \\
2006 & 455.980 & 77.116 & 6.514 & 0.154 \\
2007 & 484.017 & 102.268 & 4.660 & 0.215 \\
2008 & 447.507 & 103.200 & 3.951 & 0.253 \\
2009 & 413.743 & 77.113 & 4.845 & 0.206 \\
2010 & 413.137 & 120.844 & 3.957 & 0.253 \\
\hline
\end{tabular}

golfer who has moved to LPGA from KLPGA, as displayed in Table 18.6. The necessary and sufficient condition for positive selection, in which the best golfers leave the KLPGA (the home country) for the LPGA (the host country) and outperform the native (US) golfers, is: $\rho>\min (1 / k, k)$ where $k=\sigma_{U S} / \sigma_{K}>1$. Recall that $\sigma_{j}$ is the variance of abilities in country $j$. In 2001, the positive selection condition was satisfied if $\rho$ is greater than 0.087 since $k=11.472$ already satisfies $k>1$. Therefore, the condition for top Korean golfers to switch to the LPGA would have been satisfied in 2001. However, the condition became tighter in 2010, as $\rho$ should be greater than 0.253 and $k$ was only 3.957. The two left-most columns display the conditional expectation of earnings for golfers with $I>0$.

The expected earnings for Korean golfers who moved to the LPGA were $\$ 375,183$ in 2001, while their expected earnings if they stayed in the KLPGA were only $\$ 37,065$. This difference was large enough to induce top Korean golfers to the LPGA, even if there was a large switching cost. However, the difference in earnings has decreased continuously, and the ratio of expected earnings was only 3.4 in 2010, far less than the ratio of 10 in 2001 (see Table 18.6). Therefore, the incentive to switch tours has fallen in recent years.

The migration model also needs information about the cost of moving and the correlation of earnings in the two countries. If Korean golfers have confidence in their golfing skills, which implies a high expected correlation coefficient, the large payoff gap should motivate them to switch Tours, even in the face of language and cultural barriers. However, moving to the LPGA Tour induces various risks. For example, language difficulties and cultural misunderstanding in the US might undermine what Fried and Tauer (2011) call a golfer's 'mental fortitude', her ability to perform under 
pressure. This introduces an element of risk on the LPGA Tour that would not exist on the KLPGA Tour and can prevent a golfer from playing up to her potential. Additionally, a professional golfer travels on a weekly basis, and the average traveling distance in the LPGA Tour is much greater than in Korea. Travel thus adds to the mental strain of performing on the LPGA Tour and to the risk Korean golfers face when they move to the LPGA from the KLPGA.

Travel also adds a monetary cost to migration. According to Crosset (1995), the average annual traveling cost was between $\$ 30,000$ and $\$ 40,000$ for a golfer who participated in the 1994 LPGA Tour. This amount is approximately equal to the prize money of the 90th ranked player. However, the enormous expected payoff dominates the added risks and costs and leads Korean women to try the LPGA Tour.

Sponsorship is another incentive for Korean golfers to switch to the LPGA, since a successful career in the LPGA Tour brings lucrative sponsorships from Korean companies. According to news reports, Se Ri Pak received approximately $\$ 3$ million per year in sponsorship money from a Korean company called 'CJ Group' between 2002 and 2007. However, this incentive has diminished in recent years. For example, Shin, who contracted with a security company in 2009 , receives approximately $\$ 1.5$ million per year.

The JLPGA has a longer history than the KLPGA, and it held 34 Tours in 2010, about 55 percent more than the KLPGA. More than 250 players participated in the JLPGA Tour each year for last decade, which means that the JLPGA is quite mature and has many good golfers. The total purse in the JLPGA had been approximately half of that in the LPGA until 2008. With the decline of the LPGA purse since 2008, the total purses on the two Tours have become roughly equal. The difference in purses between the JLPGA and KLPGA Tours explains why Korean golfers, but not Japanese golfers, entered the LPGA in large numbers. Considering the various costs incurred on the LPGA Tour, a doubling of the total purse may not be sufficient to lead Japanese women golfers into the LPGA.

\subsection{MIGRATION INTO THE LPGA AND GOLF SKILLS}

\subsubsection{The Difference in Migration Patterns between the PGA and the LPGA}

This subsection explains why many Korean women have moved from the KLPGA to the LPGA, but relatively few Korean men have moved to the 


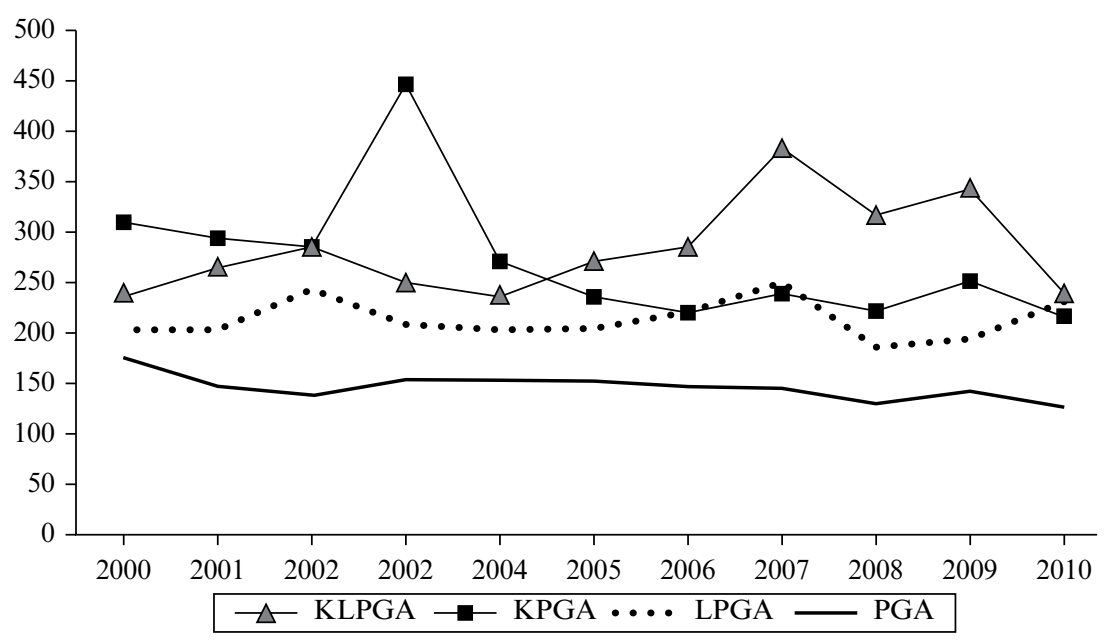

Figure 18.5 Herfindahl-Hirschman index of prize money

PGA, even though the prize money gap between the PGA and the KPGA is even wider than that between the LPGA and the KLPGA. While a handful of Korean golfers have been regular members of the PGA and a few of them have enjoyed successful careers, the performance of Korean men in the PGA has been far below the performance of Korean women in the LPGA. We show below that this disparity might result from differences in the intensity of competition on the two Tours.

Figure 18.5 compares the competition level of the men's and women's golf Tours in the US and Korea using temporal variations in the Herfindahl-Hirschman index (HHI) for the four golf Tours. The HHI is a measure of the concentration of firms in an industry, which reflects the degree of competition in the industry. To measure competition on the golf Tours, we calculate the concentration of prize money for individual golfers. We assume that a golf Tour and an individual golfer resemble an industry and a firm, respectively, and that each Tour consists of 100 golfers. We collected the data of the top 100 prize money winners and calculated the HHI as follows:

$$
H H I=\frac{\sum_{i=1}^{100} s_{i}^{2}}{T}, s_{i}=100 \cdot \frac{M_{i}}{T},
$$

where $M_{i}$ is golfer $i$ 's prize money and $T$ is the sum of the prize money for the top 100 golfers. The HHI ranges from 0 to 10,000 , with larger numbers reflecting less competition. 
From 2000 to 2010, the HHI of the PGA was the lowest of the four Tours, and there has been little temporal variation in this figure. This implies that the PGA Tour is the most competitive of the four, and that its competition level has remained relatively constant over the 2000s. Aside from the competition of the professional Tours, the probability of earning a PGA Tour card is also much slimmer than the probability of earning an LPGA Tour card. For example, 1,389 players applied for the 2010 PGA Tour qualifying tournament, while only 330 players applied for the 2010 LPGA Tour qualifying tournament. In Korea, the KLPGA evidences tighter competition than KPGA in the first half of the 2000s, even though the KPGA has grown increasingly competitive over the past five seasons.

On the women's Tours, Figure 18.5 shows that the HHI gap between the LPGA and the KLPGA was very narrow in 2000-06 and became slightly wider in 2007-09. However, the levels of competition were more or less equal to one another in the 2010 season. The similarity in the HHIs implies that the entry barrier was not high for Korean women who had already been successful in the KLPGA. Still, the uncertain benefits and costs of moving from her homeland to the LPGA Tour might make a risk-averse woman reluctant to transfer to the LPGA unless she has a high expectation of a successful career there.

Among women, the relatively unbalanced competition for prize money in the LPGA helps successful Koreans anticipate a high probability of success in the US. In contrast, the PGA is much more competitive than the KPGA, though this gap has narrowed somewhat in the second half of the 2000s. The tight competition in the PGA Tour and the difficulty inherent in passing the qualifying tournament has set a high entry barrier for foreign golfers. As the KPGA Tour was the least balanced of the four Tours in the first half of the 2000s, top Korean men enjoyed monopoly earning power in the KPGA, and were thus less likely to pursue professional careers in the PGA. Additionally, some LPGA tournaments, but no PGA tournaments, are held in Korea. This implies that Korean women have greater access to the LPGA. In fact, several Korean golfers earned their LPGA Tour cards solely by winning LPGA tournaments held in Korea.

In the context of the immigration model, Korean golfers have information on all the variables except $\varepsilon_{U S}$ in the index function (equation (18.3)). The insignificant difference in the level of competition between the LPGA and the KLPGA leads top Korean female golfers, whose $\varepsilon_{K}$ are positive and large, to expect $\varepsilon_{U S}>0$, which implies a high probability of migrating. On the other hand, tight competition in the PGA leads top Korean men to expect that $\varepsilon_{U S}<0$, suggesting a low probability of migrating. 


\subsubsection{Golf Skills of Korean Women in the LPGA}

The success of migrants to the LPGA in the late 1990s opened the door for many young Korean women to switch their affiliation to the LPGA in the 2000s. This raises the question, 'What are the main sources of their success?' Korean women may simply have better golf skills, the result of training and natural talent. Alternatively, they may be more efficient at earning prize money than other golfers with comparable skills. In this subsection, we limit ourselves to comparing golf skills. We apply the estimation results from previous studies to our data to analyze how the different aspects of the game translate into an advantage or disadvantage for Korean golfers.

We show below that Korean women can drive more accurately and putt better than the league average, but their driving distance is less than the league average. Greater accuracy with less power is thus a characteristic of the average Korean women golfer. The three left-most columns in Table 18.7 compare four variables showing the golf skills of Korean and non-Korean golfers. These statistics are based on all LPGA members who participated in at least one tournament each year from 2004 to 2010 . The average number of players included in the calculation is about 150 per year.

From 2004 to 2010, we calculate annual averages of driving distance $(D D)$, driving accuracy $(D A$, the percentage of times a driven ball lands on the fairway), green-in-regulation (GIR), and the number of putts (PUTT). Over the period, the average driving distance of Koreans is consistently shorter than that of non-Koreans. This may be attributable to the physical differences between Asian and Western golfers, as Western players are generally larger than Asian players, even though this physical gap has narrowed somewhat. The average height of Western women who are the top 20 of the 2010 Rolex ranking list is $170.5 \mathrm{~cm}$, corresponding to an approximate $4 \mathrm{~cm}$ height advantage over Korean women.

Table 18.7 Golf skills and their effects on score and prize money in 20042010: comparison between Koreans and non-Koreans (Others)

\begin{tabular}{lrrrcc}
\hline Variables & Korean: A & Others: B & A - B & $\begin{array}{c}\text { Effects on } \\
\text { score }\end{array}$ & $\begin{array}{c}\text { Effects on prize } \\
\text { money }\end{array}$ \\
\hline DD & 247.270 & 248.790 & -1.520 & -0.046 & $-9.804^{*}$ \\
$D A$ & 70.179 & 68.106 & 2.073 & 0.053 & 11.387 \\
GIR & 63.833 & 63.787 & 0.046 & 0.004 & 0.955 \\
PUTT & 29.503 & 29.989 & -0.486 & 0.334 & 71.754 \\
\hline
\end{tabular}

Note: * Thousand US dollars. 
Korean women have an edge in driving accuracy. The difference between Koreans and Others is about 2 percent throughout the 2004-10 period. GIR, which is determined by driving and iron shot skills, remains fairly steady over time. Therefore, the relative iron shot performance of Koreans is indeterminate, since the abilities of driving power and accuracy counteract one another, and the GIR is close to the league average. However, Koreans appear to retain a significant edge in putting. The average number of putts per round for Koreans is consistently smaller (by about 0.5 ) than that of Others.

Park and Lee (2011) evaluate the effects of various golf skills on score and prize money earned using panel data for 132 female golfers in the LPGA and determine that driving shots, iron shots, sand bunker shots, and putting skills all significantly influence scoring and prize money. We apply the estimates in Tables 2 and 4 of Park and Lee to the difference of average skills between Koreans and Others to calculate the effect of each skill on both score and prize money. These impacts appear in the last two columns in Table 18.7. Our calculation demonstrates that the putting advantage is a principal source of successful performance by Korean golfers in the LPGA. The advantage in PUTT allows Korean golfers to earn $\$ 71,754$ more in prize money on average.

\subsection{CONCLUSION}

In this chapter, we have discussed the reasons for the sudden influx of Korean women into the LPGA in the 2000s. We also place the influx in the broader context of international migration using the analytical framework of Borjas (1987, 1994). Because Korean women have higher expected earnings than Japanese women relative to the earnings in their home country, they are more likely to migrate. Analogously, Korean woman expect higher earnings from playing on the LPGA than Korean men expect from playing on the PGA, so they are more likely to migrate than Korean men.

The KLPGA has grown to become one of the five major ladies' professional golf Tours upon which the Rolex World Rankings are based. The mature KLPGA has allowed young women to apply their golf skills in competitive settings and to accumulate experience and ability as professional golfers. The huge difference in total prize money and in the number of tournaments between the KLPGA and the LPGA provided the best Korean golfers with an incentive to migrate. Moreover, success as an LPGA golfer led to enormous publicity and lucrative sponsorships in Korea. The incentives for Korean women to switch from the KLPGA 
to LPGA were sufficiently large to compensate for the possible risks and costs of playing in the LPGA. We show that competitive balance in the LPGA is more or less similar to that in the KLPGA, which implies that there is a high probability that a golfer who is successful in the KLPGA will perform well in the LPGA.

The relatively unbalanced competition in the LPGA Tour stands in stark contrast to the tightly balanced competition in the PGA Tour, in which Asian golfers have proven less successful, and provides an added incentive for migration to Korean women. Finally, Korean women's golf skills of accuracy and putting are advantages for the average Korean woman, while her weak driving power is a disadvantage. Putting ability appears to be a significant factor contributing to the competitiveness of Korean golfers in the LPGA.

We can now speculate what the future will bring. The payoff difference between the two ladies' golf Tours has narrowed dramatically in recent years, owing to a sizable decline of the total purse in the LPGA after the 2008 season and a steady increase in the KLPGA's purse. Between 2001 and 2010, the total prize money on the KLPGA Tour has risen from 10 percent to approximately 30 percent of the LPGA's prize money. As shown in Figure 18.3, the KLPGA has offered at least 20 tournaments per year since 2007. The same trend can be observed in mean prize money and within-Tour variations (see Tables 18.4 and 18.5).

As the popularity of the KLPGA has grown, sponsorship has generally followed. According to a news release from May 2008, the TV ratings of live KLPGA tournaments have increased gradually, whereas the viewing ratings of the LPGA in Korea have decreased, reflecting the increasing popularity of the KLPGA and the decreasing popularity of the LPGA in Korea (Jungang Daily News, 2008). In addition, we have shown that the earning variance ratio, $k$, has consistently decreased, from 11.47 in 2001 to 3.96 in 2010 . Therefore, the likelihood that talented golfers will migrate has fallen.

In Japan, the JLPGA's purse reached 75 percent of the LPGA's, and the number of tournaments surpassed that of the LPGA by seven in 2010. Therefore, the sum of prize money in the JLPGA and KLPGA combined exceeded that of the LPGA in 2010. Because Japan is so close to Korea, Korean and Japanese golfers can participate in tournaments in both the KLPGA and the JLPGA if they hold both Tour cards. About 20 Korean golfers have participated in the JLPGA Tour since 2005. Korean players contributed only about 4 percent of players in JLPGA in the early 2000s, but this percentage has doubled in the late 2000s ( 8.5 percent in 2010).

Since Korean women's incentives for switching from the KLPGA to the LPGA are smaller than in previous years, we expect the number of new 
Korean entrants into the LPGA to decline in the future; we also anticipate that some less-successful Korean golfers will return to the KLPGA Tour. In 2006, 20 Korean women ranked among the top 150 but did not play in the LPGA, and this number increased to 32 in 2010. If the LPGA hopes to encourage this trend, it might consider lengthening golf courses in order to exploit the Western women's relative advantage of driving power over Korean women, which might ultimately bring more American fans to the LPGA.

\section{NOTE}

* We thank two research assistants, Hansol Hwang and Woohyung Lee of Seoul National University, for their time and effort in collecting data and preparing tables and figures. The very detailed and helpful comments of the editors are gratefully acknowledged.

\section{REFERENCES}

Arrow, Kenneth J. (1998), 'What Has Economics to Say about Discrimination?', Journal of Economic Perspectives, 12(2), Spring: 91-100.

Borjas, George J. (1987), 'Self-Selection and the Earnings of Immigrants', American Economic Review, 77(4), September: 531-53.

Borjas, George J. (1994), 'The Economics of Immigration', Journal of Economic Literature, 32(4), December: 1667-717.

Crosset, Todd W. (1995), Outsiders in the Clubhouse: The World of Women's Professional Golf, Albany, NY: State University of New York Press.

Foley, Mark and Fred H. Smith (2007), 'Consumer Discrimination in Professional Sports: New Evidence from Major League Baseball', Applied Economics Letters, 14(13), October: 951-5.

Fried, Harold O. and Loren W. Tauer (2011), 'The Impact of Age on the Ability to Perform under Pressure: Golfers on the PGA Tour', Journal of Productivity Analysis, 35(1), October: 51-9.

Greenhaus, Jeffrey H., Saroj Parasuraman and Wayne M. Wormley (1990), 'Effects of Race on Organizational Experiences, Job Performance Evaluations, and Career Outcomes', Academy of Management Journal, 33(1), March: 64-86.

Hamilton, Barton Hughes (1997), 'Racial Discrimination and Professional Basketball Salaries in the 1990s', Applied Economics, 29(3), March: 287-96.

Jungang Daily News (2008), 'Sinking LPGA and Rising KLPGA: KLPGA Viewing Rating is 3 Times Higher than That of LPGA', May 16.

Kanazawa, Mark T. and Jonas P. Funk (2001), 'Racial Discrimination in Professional Basketball: Evidence from Nielsen Ratings', Economic Inquiry, 39(4), October: 599-608.

Medoff, Marshall H. (1986), 'Baseball Attendance and Fan Discrimination', Journal of Behavioral Economics, 15(1-2), Spring-Summer: 149-55.

Nardinelli, Clark and Curtis Simon (1990), 'Consumer Racial Discrimination in the Market for Memorabilia: The Case of Baseball', Quarterly Journal of Economics, 105(3), August: 575-95.

Park, Ilhyeok and Young Hoon Lee (2011), 'Efficiency Comparison of International Golfers in LPGA', Paper presented at the annual conference of the Western Economic Association, San Diego, CA, July. 
Roy, Andrew D. (1951), 'Some Thoughts on the Distribution of Earnings', Oxford Economic Papers, 3(2), June: 135-46.

Yonhap News (2009), 'Increase of Broadcasting Right Fee of LPGA Due to an Overly Heated Competition between Korean Broadcasting Companies', February 12. 